\title{
Article \\ Estimating Significant Wave Height from SAR with Long Integration Times
}

\author{
Yawei Zhao ${ }^{1,2,3} \mathbb{1}$, Jinsong Chong ${ }^{1,2,3, *}$, Zongze $\mathrm{Li}^{1,2,3}$, Xianen Wei ${ }^{1,2,3}$ and Lijie Diao ${ }^{1,2,3}$ \\ 1 National Key Lab of Microwave Imaging Technology, Beijing 100190, China; \\ zhaoyawei17@mails.ucas.ac.cn (Y.Z.); lizongze20@mails.ucas.ac.cn (Z.L.); \\ weixianen20@mails.ucas.ac.cn (X.W.); diaolijie21@mails.ucas.ac.cn (L.D.) \\ 2 Aerospace Information Research Institute, Chinese Academy of Sciences, Beijing 100190, China \\ 3 School of Electronics, Electrical and Communication Engineering, University of Chinese Academy of Sciences, \\ Beijing 100049, China \\ * Correspondence: lily@mail.ie.ac.cn; Tel.: +86-10-5888-7125
}

Citation: Zhao, Y.; Chong, J.; Li, Z.; Wei, X.; Diao, L. Estimating

Significant Wave Height from SAR with Long Integration Time. Appl. Sci. 2022, 12, 2341. https://doi.org/ 10.3390/app12052341

Academic Editor: Amerigo Capria

Received: 29 January 2022

Accepted: 22 February 2022

Published: 23 February 2022

Publisher's Note: MDPI stays neutral with regard to jurisdictional claims in published maps and institutional affiliations.

Copyright: (c) 2022 by the authors. Licensee MDPI, Basel, Switzerland. This article is an open access article distributed under the terms and conditions of the Creative Commons Attribution (CC BY) license (https:// creativecommons.org/licenses/by/ $4.0 /)$.

\begin{abstract}
Synthetic aperture radar (SAR) is an important means of estimating significant wave height with obvious advantages of all-day, all-weather, high resolution and wide swath coverage. At present, the estimation methods of significant wave height are based on visible ocean waves in SAR images. However, due to the characteristic of long integration time for low-frequency SAR (such as P-band, L-band), the ocean waves are usually invisible in SAR images. In addition, in the case that there are multiple wave systems, significant wave height of only one wave system can be estimated for the reason that only a blurred wave system can be observed in SAR images. In order to solve the above two problems, a method of estimating significant wave height from SAR with long integration times is proposed in this paper. Firstly, each ocean wave system is refocused from single-look complex (SLC) data, respectively. Then, without any additional processing, the $180^{\circ}$ ambiguity of wave propagation direction is removed based on the optimum focus setting. Finally, significant wave height is estimated in combination with azimuth cutoff, wavelength and propagation direction of ocean waves. This method is applied to two airborne SAR field data with long integration times. One case is that ocean waves are invisible in SAR images, the other is that there are two wave systems on the real ocean surface, but only one is visible in the SAR images. The results show that the proposed method can estimate significant wave height in the cases of invisible ocean waves and multiple ocean waves. The estimation results of significant wave height are compared with the European Centre for Medium-Range Weather Forecast (ECMWF) data, and the error is basically stable within $0.2 \mathrm{~m}$, which verifies the effectiveness of the proposed method.
\end{abstract}

Keywords: significant wave height; synthetic aperture radar; long integration time

\section{Introduction}

Waves are the ocean's most obvious surface feature. Significant wave height (SWH) is defined as the average of the highest one-third of the observed waves [1]. As an important parameter reflecting the characteristics of ocean waves, the accurate estimation of the significant wave height is particularly important for marine engineering, ship designing and marine transportation.

Synthetic aperture radar (SAR) has become one of the important ways to obtain ocean wave parameters with obvious advantages of all-day, all-weather, high resolution and wide swath coverage [1]. At present, the methods of estimating significant wave height can be divided into three major categories. The first type is theoretical-based methods, such as the Max-Planck Institute (MPI) [2,3], numerical wave model [4], semi-parametric retrieval algorithm (SPRA) [5] and parameterized first-guess spectrum method (PFSM) [6,7]. However, they are difficult and limited in implementation. The second is empirical methods, which are typically represented by CWAVE_ERS [8], CWAVE_ENVI [9], CWAVE_S1A [10] 
and QPCWAVE_GF3 [11]. These methods can only process specific SAR data. The third method is based on the relationship between the significant wave height and the azimuth cutoff [12-14]. However, all of the above methods are based on visible ocean waves in SAR images.

Actually, due to the random motion of the ocean waves, the ocean waves in the SAR images will be extremely blurred or even invisible $[15,16]$. For low-frequency SAR (such as P-band, L-band) data which have the characteristic of long integration time, the following two problems are more prominent. The ocean waves are usually invisible in SAR images. It is impossible to estimate significant wave height by means of the present methods. On the other hand, in the case that there are multiple wave systems, significant wave height of only one wave system can be estimated using the present methods for the reason that only a blurred wave system can be observed in SAR images.

In order to solve the problems that the present methods cannot estimate the significant wave height when the ocean waves are invisible and that can estimate the significant wave height of only one wave system in the case of multiple wave systems, a method of estimating significant wave height from SAR with long integration times is proposed in this paper. The proposed method is suitable for SAR data with long integration times. The clear SAR images of ocean waves can be obtained by refocusing, breaking through the limitation that the present methods cannot estimate the significant wave height when the wave texture is invisible from SAR with long integration times. Firstly, the azimuth cutoff is calculated. Then, each ocean wave system is refocused from single-look complex (SLC) data, respectively. After obtaining the optimum refocused SAR image of different wave systems, the wavelength and propagation direction of each wave system are calculated. Meanwhile, according to the optimum focus setting, the $180^{\circ}$ ambiguity of wave propagation direction is removed without any additional processing. Finally, significant wave heights are estimated. Two airborne SAR data with long integration times are employed to verify the proposed method. One case is that ocean waves are invisible in SAR images, the other is that there are two wave systems on the real ocean surface but only one is visible in the SAR images. The results are compared with the European Centre for medium-Range Weather Forecast (ECMWF) data, which demonstrate the effectiveness of the proposed method.

The remainder of the paper is organized as follows. In Section 2, the proposed method is introduced in detail. In Section 3, the experimental results of airborne SAR data with invisible ocean waves and two ocean wave systems are given. In Section 4, the results are compared with ECMWF data, which verified the effectiveness of the proposed method, and the sensitivity of the significant wave height is analyzed. Finally, conclusions are drawn in Section 5.

\section{Estimating Significant Wave Height from SAR with Long Integration Times}

In this section, a method of estimating significant wave height from SAR with long integration times is proposed, which is designated for the SAR single-look complex (SLC) data. The flow chart of the proposed method is shown in Figure 1. As can be seen, the method is divided into six parts: pre-processing, azimuth cutoff calculation, ocean wave refocusing, scanning distortion calibration, wavelength and propagation direction calculation of $n$th ocean wave and significant wave height estimation. The above six parts will be detailed below.

\subsection{Pre-Processing}

In order to avoid the interference of artificial targets targets on the sea surface, a sub-block data is chosen from the SAR SLC data at first. The sub-block is selected according to the following two constraints: (1) the sub-block needs to contain ocean waves; and (2) the sub-block does not include other interference information, such as ship, oil slicks. 


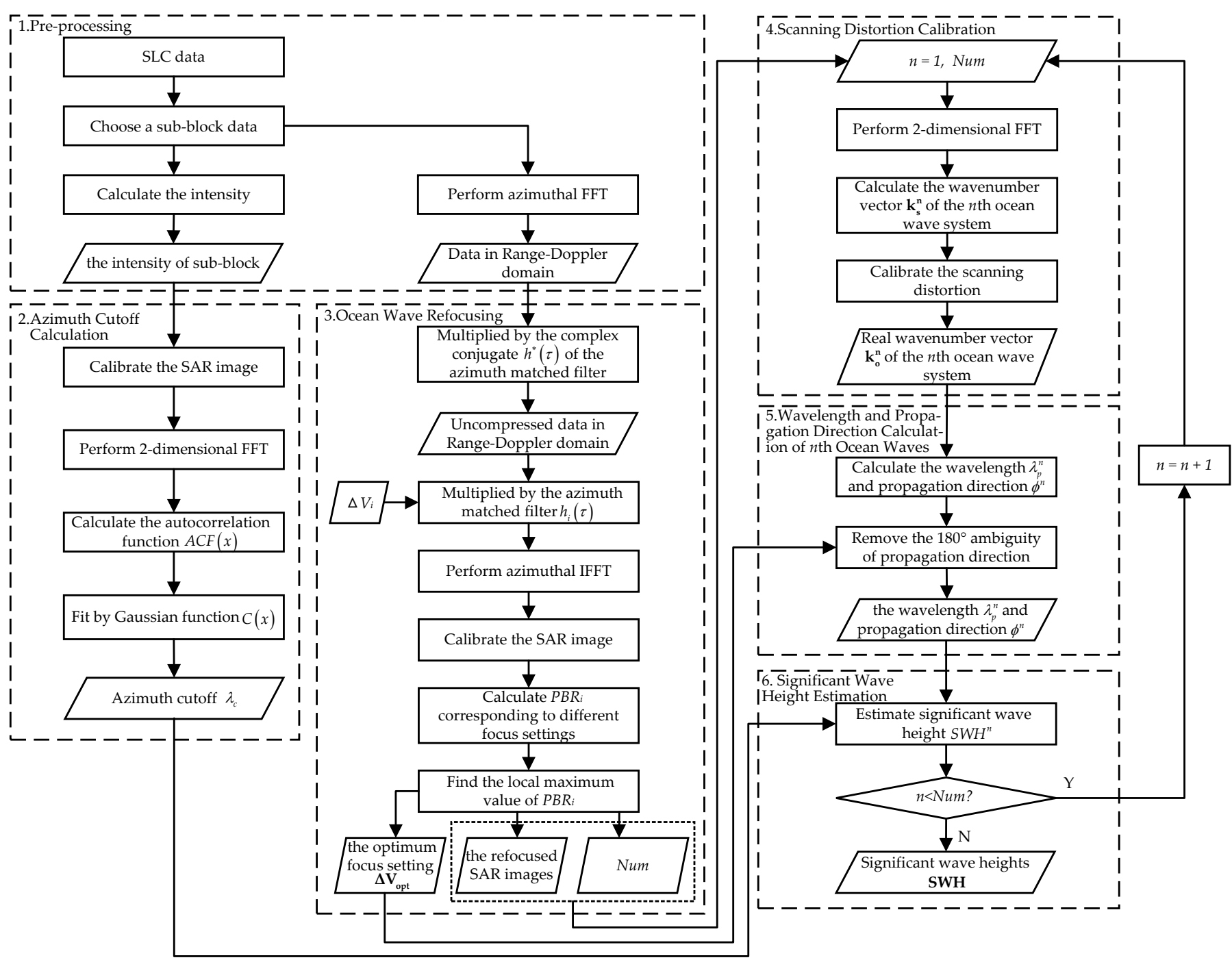

Figure 1. Flow chart of the proposed method.

Then, two operations need to be performed for the sub-block data. One operation is that the sub-block amplitude data is calculated for azimuth cutoff calculation. The other is that a fast Fourier transform (FFT) along the azimuth is performed, obtaining the Range-Doppler domain data, which is used for ocean wave refocusing.

\subsection{Azimuth Cutoff Calculation}

Azimuth cutoff $\lambda_{c}$ is the minimum detectable azimuth wavelength by SAR system $[17,18]$. In order to obtain the azimuth cutoff $\lambda_{c}$, it is necessary to calculate the azimuthal autocorrelation function $A C F(x)$. Then, Gaussian function $C(x)$ is used to fit $A C F(x)$.

In this subsection, the amplitude data needs to be calibrated in the first instance, which includes slant-to-ground conversion, multi-look processing, and range energy normalization [19]. After the above calibrations, the SAR image is transformed into the wavenumber domain by two-dimensional FFT (2D-FFT). $\lambda_{c}$ is computed by fitting a Gaussian function $C(x)$ to the $A C F(x)$. The Gaussian function is written as,

$$
C(x) \sim \exp \left(-\left(\frac{\pi x}{\lambda_{c}}\right)^{2}\right)
$$

where $x$ is the azimuth distance. 


\subsection{Ocean Wave Refocusing}

In order to solve the problems of invisible ocean waves and only a weak wave system in the case of multiple wave systems can be observed acquired by long integration time SAR, the ocean wave refocusing method based on optimum focus setting will be introduced in this section.

Focus setting $\Delta V$ is defined as the difference between platform speed $V$ and azimuth matched filter speed $U$, namely,

$$
\Delta V=V-U
$$

The focus setting that makes the target to be best-focused is called the optimum focus setting $[20,21]$. The contrast of ocean waves can be improved by changing the focus setting, and the optimum focus setting is obtained according to the azimuth phase speed [22]. However, the ocean waves are usually invisible and obtained by the long integration time SAR, which will result in the optimum focus setting being unable to be calculated by the present methods. Accordingly, it is a failure to achieve the ocean wave refocusing. In addition, for the case of multiple ocean wave systems and only a weak wave can be observed, the present methods can only obtain the optimum focus setting of an ocean wave system, which will result in that only an ocean wave system can be refocused. In order to solve the above two problems, this section will improve the present methods. The optimum focus setting is calculated by setting a focus setting variation section and finding the local maximum value of the peak-to-background ratio (PBR), and further the refocused SAR images of ocean waves are obtained. Next, the improved method is described.

In this subsection, in order to obtain the uncompressed data in Range-Doppler domain, the Range-Doppler domain data is multiplied by the complex conjugate $h^{*}(\tau)$ of the azimuth matched filter used in imaging process. The complex conjugate $h^{*}(\tau)$ of the azimuth matched filter is

$$
h^{*}(\tau)=\exp \left(-j \frac{2 \pi V^{2} \tau^{2}}{\lambda R}\right)
$$

where $V$ is the platform speed, $\tau$ is the azimuth time, $\lambda$ is the radar wavelength, and $R$ is the slant range. The next step is to set a focus setting variation section $\Delta V_{i} \in[V-50, V+50]$. And new azimuth matched filter functions $h_{i}(\tau)$ are generated,

$$
h_{i}(\tau)=\exp \left(j \frac{2 \pi U_{i}^{2} \tau^{2}}{\lambda R}\right)
$$

where the velocity parameters $U_{i}=V-\Delta V_{i}$ of the azimuth matched filter. Refocusing results under different focus settings are obtained by means of the new azimuth matched filter functions $h_{i}(\tau)$, and the refocused image is calibrated, which including slant-toground conversion, multi-look processing and range energy normalization [19].

Next, the calibrated images are compared to determine the optimum focus setting. Therefore, the SAR images corresponding to different focus settings $\Delta V_{i}$ are transformed into the two-dimensional wavenumber domain, and the peak-to-background ratio (PBR) of the wavenumber spectral energy is calculated. The definition of PBR is as follows [23,24]:

$$
P B R=\frac{\left(S_{I}\right)_{\max }}{\left\langle S_{\text {noise }}\right\rangle}
$$

among them, $\left(S_{I}\right)_{\max }$ and $\left\langle S_{\text {noise }}\right\rangle$ represent the peak value and noise floor of the SAR image spectrum, respectively.

The peak-to-background ratio $P B R_{i}$ is normalized to obtain the curve of normalized $P B R_{i}$ with focus setting $\triangle V_{i}$. According to the focus setting corresponding to the $n$th local maximum value of $P B R_{i}$, the optimum focus setting $\triangle V_{o p t}^{n}$ of the $n$th ocean wave system is obtained. The optimum focus setting of Num ocean wave systems is expressed as

$$
\Delta \mathbf{V}_{\mathbf{o p t}}=\left[\Delta V_{o p t}^{n}\right], 1 \leq n \leq N u m
$$


$\Delta \mathbf{V}_{\text {opt }}$ will be used to solve the $180^{\circ}$ ambiguity of wave propagation direction. In addition, the SAR images corresponding to the optimum focus setting and the number Num of local maximum value will be used in the subsequent estimating significant wave height.

\subsection{Scanning Distortion Calibration}

Next, the optimum refocused SAR image corresponding to each wave system is processed by the scanning distortion calibration, wavelength and propagation direction calculation of $n$th ocean wave and significant wave height estimation. At first, this subsection needs to initialize the $n$th wave system and the number Num of wave systems, where $n=1$, and the Num is given by the number of local maximum value of $P B R_{i}$ in the Section 2.3.

In order to obtain the wavenumber vector $k_{o}^{n}$ the $n$th wave system on the real ocean surface, it is necessary to calibrate the SAR image scanning distortion caused by the velocity bunching modulation. The optimum refocused SAR image corresponding to the $n$th ocean wave system is transformed into the two-dimensional wavenumber domain, and the wave number vector $\mathbf{k}_{\mathbf{s}}^{\mathbf{n}}$ of the $n$th ocean wave system is obtained, which is expressed as

$$
\mathbf{k}_{\mathbf{s}}^{\mathbf{n}}=\left[\begin{array}{ll}
k_{r s}^{n} & k_{a s}^{n}
\end{array}\right]
$$

where $k_{r s}^{n}$ and $k_{a s}^{n}$ are the range wavenumber and the azimuth wavenumber of the $n$th ocean wave system in the SAR image, respectively.

The range wavenumber $k_{r o}^{n}$ of the $n$th ocean wave system on the real ocean surface is equal to that $k_{r S}^{n}$ of the $n$th ocean wave system in the SAR image. However, due to the scanning distortion, the azimuth wavenumber $k_{a o}^{n}$ of the $n$th ocean wave system on the real ocean surface is typically different from that $k_{a s}^{n}$ of the $n$th ocean wave system in the SAR image $[18,25]$, which can be expressed as

$$
k_{a o}^{n}=k_{a s}^{n}+\frac{\sqrt{g k_{o}^{n}}}{V}
$$

where $g$ is the acceleration of gravity, $k_{o}^{n}=\sqrt{k_{a 0}^{n}{ }^{2}+k_{r o}^{n} 2}$ is the wavenumber of the $n$th ocean wave system in the real ocean surface, and $V$ is the platform speed. By solving Equation (8), the wavenumber vector $k_{o}^{n}$ of the $n$th ocean wave system in the real ocean surface can be obtained, which is

$$
k_{o}^{n}=\left[\begin{array}{ll}
k_{r o}^{n} & k_{a o}^{n}
\end{array}\right]
$$

\subsection{Wavelength and Propagation Direction Calculation of $n$th Ocean Waves}

Since the parameters such as wavelength and propagation direction are required in estimating significant wave height, the equations of the $n$th wavelength and propagation direction are introduced below. The $180^{\circ}$ ambiguity of wave propagation direction is removed through the optimum focus setting directly without any additional processing.

\subsubsection{Wavelength Calculation of $n$th Ocean Wave}

The $n$th wave wavelength $\lambda_{p}^{n}$ can be calculated from its corresponding wavenumber, namely,

$$
\lambda_{p}^{n}=\frac{2 \pi}{\sqrt{k_{a o}^{n}+k_{r o}^{n} 2}}
$$




\subsubsection{Propagation Direction Calculation of $n$th Ocean Wave}

In order to facilitate the subsequent $180^{\circ}$ ambiguity removal of wave propagation direction, the propagation direction $\phi^{n}$ of $n$th ocean waves is defined as the angle between wave propagation direction and range direction. It is calculated as

$$
\phi^{n}= \begin{cases}-\tan ^{-1} \frac{k_{a o}^{n}}{k_{r o}^{n}}, & k_{r o}^{n}>0, k_{a o}^{n}<0 \\ 180^{\circ}-\tan ^{-1} \frac{k_{a o}^{n}}{k_{k o}^{n},} & k_{r o}^{n}<0 \\ 360^{\circ}-\tan ^{-1} \frac{k_{a o}^{n}}{k_{r o}^{n}}, & k_{r o}^{n}>0, k_{a o}^{n}>0\end{cases}
$$

The propagation direction of $n$th ocean waves calculated by Equation (11) exists $180^{\circ}$ ambiguity. In order to avoid the influence of $180^{\circ}$ ambiguity on estimating significant wave height, it is necessary to de-blur. The following will introduce the $180^{\circ}$ ambiguity removal method.

\subsection{3. $180^{\circ}$ Ambiguity Removal of Wave Propagation Direction}

At present, cross-spectra is an important method to removal of $180^{\circ}$ ambiguity [26]. In order to ensure high signal-to-noise ratio, the wavelength estimation needs to satisfy the time separation between two individual-look SAR images is short enough, while the propagation direction estimation needs to satisfy that is long enough [27]. It needs to calculate two SAR image cross spectra, and the time separation optimization is also a complex problem [27]. Compared with the cross-spectra method, the proposed method is simpler and does not require any additional processing to remove $180^{\circ}$ ambiguity using the optimum focus setting.

The relationship between the optimum focus setting and the wave propagation direction is explained below at first. When SAR observes the ocean, the Doppler frequency shift caused by the motion of the ocean waves is [21]

$$
f_{D}=\frac{2 V\left(V-C^{n}\right) \tau}{\lambda R}
$$

where $C^{n}$ is the azimuth phase velocity of the $n$th wave system. When the propagation direction is the same as the azimuth direction, $C^{n}$ is positive. When the propagation direction is opposite to the azimuth direction, $C^{n}$ is negative. Hence the optimum focus is obtained when

$$
U^{2}=V\left(V-C^{n}\right)
$$

This gives a optimum focus setting of $n$th wave system

$$
\Delta V_{o p t}^{n} \approx \frac{C^{n}}{2}
$$

Due to the complexity of ocean wave motion, the real optimum focus setting for surface waves may deviate from Equation (14) under some conditions [22,28]. However, in general, the optimum focus setting is close to half of the azimuthal phase velocity. So, the optimum focus setting is used to remove the $180^{\circ}$ ambiguity without any additional processing.

When $\Delta V_{o p t}^{n}>0$, the propagation direction is the same as the azimuth direction. When $\Delta V_{o p t}^{n}<0$, the propagation direction is opposite to the azimuth direction. So, after we remove $180^{\circ}$ ambiguity, the propagation direction $\phi^{n}$ is

$$
\phi^{n}= \begin{cases}\phi^{n}-180^{\circ}, & \Delta V_{o p t}^{n}<0 \cap \phi^{n} \in\left(180^{\circ}, 360^{\circ}\right] \\ \phi^{n}+180^{\circ}, & \Delta V_{o p t}^{n}>0 \cap \phi^{n} \in\left(0^{\circ}, 180^{\circ}\right] \\ \phi^{n}, & \text { else }\end{cases}
$$




\subsection{Significant Wave Height Estimation}

Combining the azimuth cutoff $\lambda_{c}$, the wavelength $\lambda_{p}^{n}$ of the $n$th wave system, the wave propagation direction $\phi^{n}$ and the radar parameters, the significant wave height is calculated by [14]

$$
S W H^{n}=\frac{0.3608}{\beta \sqrt{G^{n} g} \sqrt{\tanh \left(2 \pi d / \lambda_{p}^{n}\right)}} \lambda_{c} \sqrt{\lambda_{p}^{n}}
$$

where,

$$
\begin{gathered}
G^{n}=1-0.5 \sin ^{2} \theta\left[1+\frac{\pi}{B} / \sinh \left(\frac{\pi}{B}\right) \cos \left(2\left(\phi^{n}+90^{\circ}\right)\right)\right] \\
\beta=\frac{R}{V}
\end{gathered}
$$

where $d$ is the water depth, $B=2.44, R$ is the slant range, and $V$ is the platform speed. When $d \gg \lambda_{p}^{n} / 2, \sqrt{\tanh \left(2 \pi d / \lambda_{p}^{n}\right)}=1$, Equation (16) can be written as

$$
S W H^{n}=\frac{0.3608}{\beta \sqrt{G^{n} g}} \lambda_{c} \sqrt{\lambda_{p}^{n}}
$$

After the estimating significant wave height of all ocean wave systems is completed, significant wave heights of all systems are output

$$
S W H=\left[S W H^{n}\right], n \in[1, N u m]
$$

\section{Experiments of Estimating Significant Wave Height from SAR with Long Integration Times}

In order to verify the effectiveness of the proposed method, experiments of estimating significant wave height from SAR with long integration times will be carried out in this section. Two representative data are selected. One is the case where the waves are invisible, which cannot be directly used to estimate significant wave height by current methods. The other is the case where there are two ocean wave systems in the real ocean surface. However, only a weak ocean wave system can be observed in the SAR image. If no processing is performed, only an ocean wave system can be achieved estimating significant wave height. The experimental results of these two cases are given below.

\subsection{Case 1-Invisible Ocean Waves from SAR with Long Integration Times}

The situation where the ocean waves are invisible is common from SAR with long integration times. In this subsection, the proposed method is applied to the P-band field data. The experimental data comes from the sea trial experiment conducted by the Aerospace Information Research Institute, Chinese Academy of Sciences covering South China Sea. It was collected on 11 October 2014. The integration time is $23 \mathrm{~s}$. The radar system parameters are shown in Table 1.

Table 1. Radar system parameters.

\begin{tabular}{ccc}
\hline Parametric Name & Parametric Symbol & Parametric Value \\
\hline Radar wavelength $(\mathrm{m})$ & $\lambda$ & 0.5 \\
Platform height $(\mathrm{m})$ & $H$ & 8600 \\
Slant range of scene center $(\mathrm{m})$ & $R_{0}$ & 18,000 \\
Platform speed $(\mathrm{m} / \mathrm{s})$ & $V$ & 122 \\
Integration Times $(\mathrm{s})$ & $T_{0}$ & 23 \\
\hline
\end{tabular}

The SAR image obtained by the traditional imaging method is shown in Figure 2a, and the image spectrum is shown in Figure 2b. As shown in Figure 2a, the ocean waves are 
completely invisible. Meanwhile, the corresponding wave spectrum cannot distinguish the wave characteristics shown in Figure $2 b$.

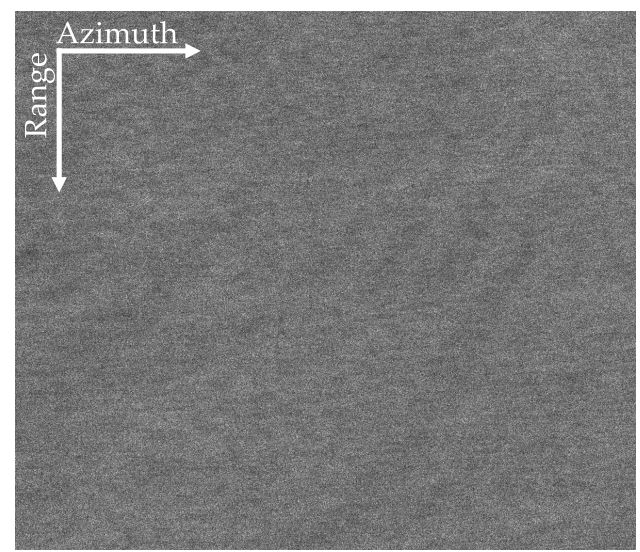

(a)

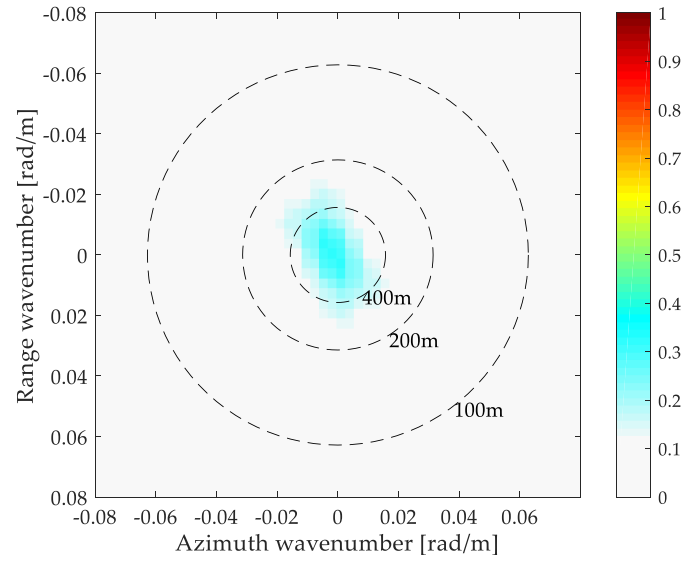

(b)

Figure 2. SAR image with invisible waves acquired by traditional imaging method and corresponding spectrum. (a) SAR image with invisible waves. (b) Spectrum corresponding to SAR image.

The azimuthal autocorrelation function obtained from the SAR image spectrum is shown in Figure 3. Gaussian fitting is performed according to the Equation (1), and the azimuth cutoff $\lambda_{c}=86.72 \mathrm{~m}$ is calculated, which will be used to estimate significant wave height later.

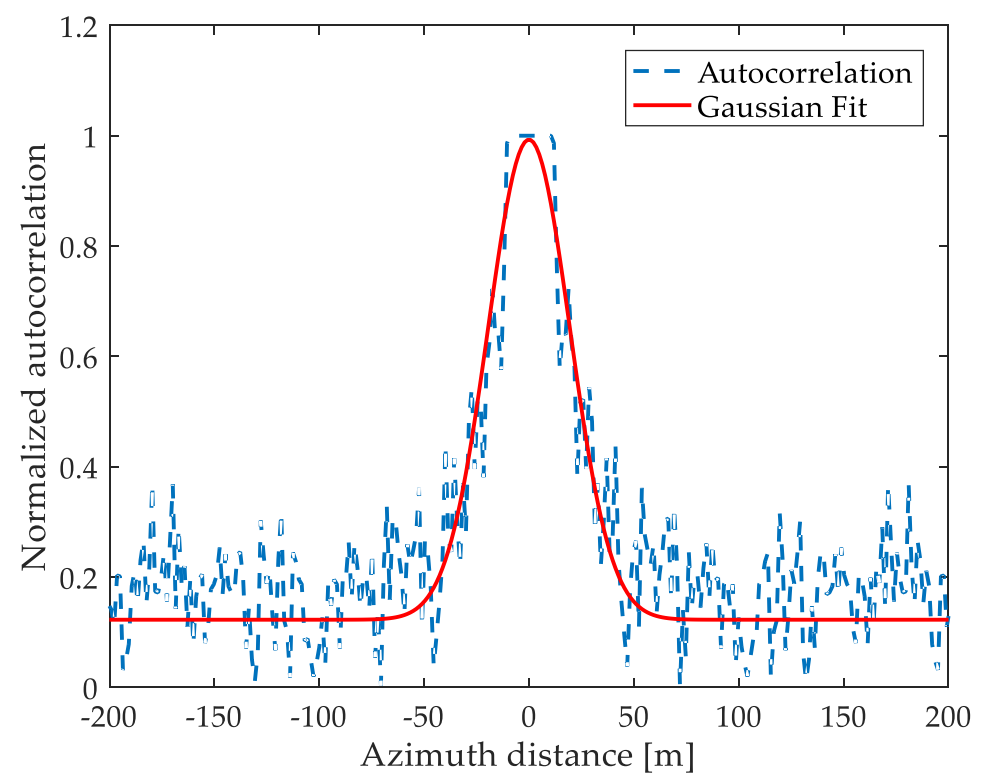

Figure 3. Azimuthal autocorrelation function and its Gaussian fitting results.

Since the ocean waves are completely invisible, the estimation of significant wave height cannot be carried out. So it is necessary to refocus ocean waves. The SAR SLC data shown in Figure 2a is refocusing. By traversing the focus setting variation section $\Delta V_{i} \in[V-50, V+50]$, the curve of the normalized peak-to-background ratio obtained changing with focus setting is shown in Figure 4. 


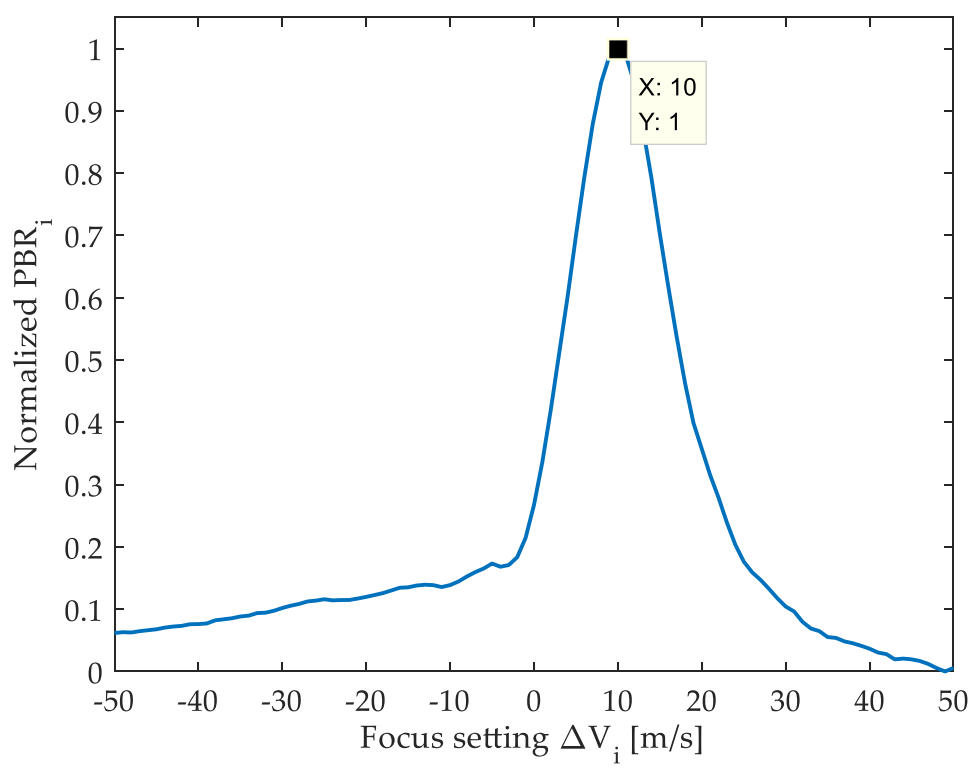

Figure 4. Normalized peak-to-background ratio curve with focus setting.

As shown in Figure 4, the normalized peak-to-background ratio has only one local maximum value, indicating that there is only one wave system on the the real ocean surface. When $\Delta V_{o p t}^{1}=10 \mathrm{~m} / \mathrm{s}$, the refocusing quality of the ocean waves is best shown in Figure $5 \mathrm{a}$. The corresponding wave spectrum is shown in Figure $5 b$.

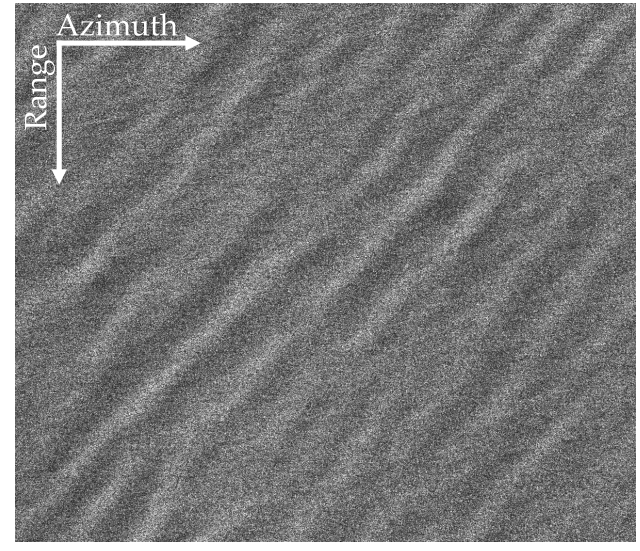

(a)

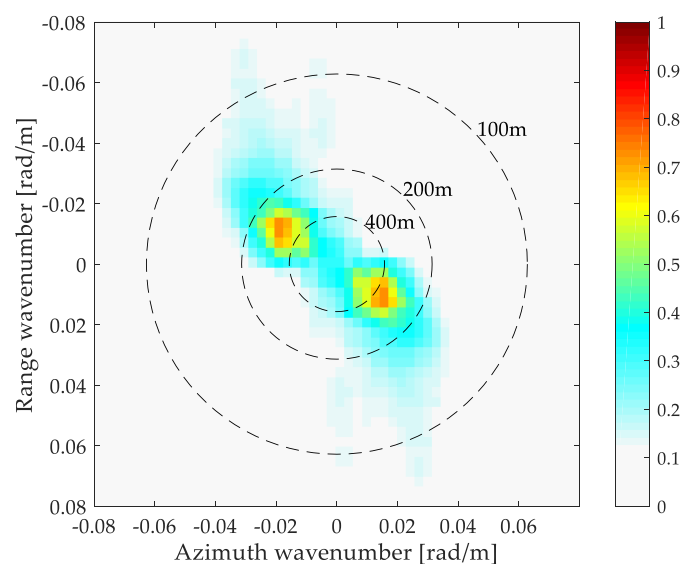

(b)

Figure 5. Refocused SAR image of ocean waves and corresponding spectrum. (a) Refocused SAR image with invisible waves. (b) Spectrum corresponding to refocused SAR image.

As shown in Figure 5a, it can be found that the wave texture is clearly visible. Meanwhile, the wave spectrum is highlighted in Figure $5 b$, which is more conducive to estimate significant wave height. Using the process shown in Figure 1, the wavelength $\lambda_{p}^{1}=233.85 \mathrm{~m}$ of ocean waves can be obtained. Due to $\Delta V_{o p t}^{1}>0$, the wave propagation direction after $180^{\circ}$ ambiguity removal is $\phi^{1}=299.19^{\circ}$. Finally, the significant wave height $S W H^{1}=1.51 \mathrm{~m}$ is calculated by Equation (19).

\subsection{Case 2-Multiple Ocean Waves from SAR with Long Integration Times}

In common, when long integration time SAR is used to observe the ocean with multiple wave systems, only a wave system can be observed in the SAR images obtained by traditional imaging methods. In order to verify the effectiveness of the proposed method for estimating significant wave height of multiple ocean systems, the proposed method is 
applied to the L-band field data in this subsection. However, since there are no SAR data of multiple wave systems, the SAR data of two wave systems is selected for experimental verification. The experimental data comes from the sea trial experiment conducted by the Aerospace Information Research Institute, Chinese Academy of Sciences covering South China Sea. It was collected on 14 September 2014. The radar system parameters are shown in Table 2.

Table 2. Radar system parameters.

\begin{tabular}{ccc}
\hline Parametric Name & Parametric Symbol & Parametric Value \\
\hline Radar wavelength $(\mathrm{m})$ & $\lambda$ & 0.23 \\
Platform height $(\mathrm{m})$ & $H$ & 8100 \\
Slant range of scene center $(\mathrm{m})$ & $R_{0}$ & 13,000 \\
Platform speed $(\mathrm{m} / \mathrm{s})$ & $V$ & 117 \\
Integration Times $(\mathrm{s})$ & $T_{0}$ & 6 \\
\hline
\end{tabular}

The SAR image obtained by the traditional imaging method is shown in Figure $6 a$ while the image spectrum is shown in Figure 6b. As shown in Figure 6a, it can be found that wave textures are very weak, and the corresponding wave spectrum characteristics are also relatively weak, which brings difficulties to estimating significant wave height. In addition, only a wave system can be observed in SAR images.

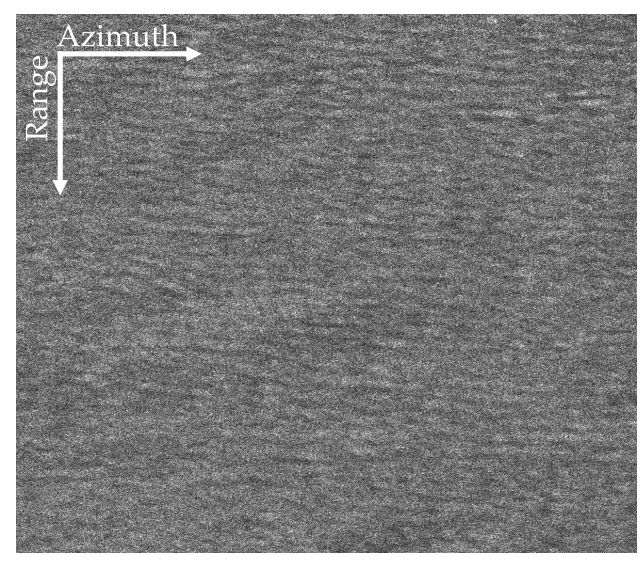

(a)

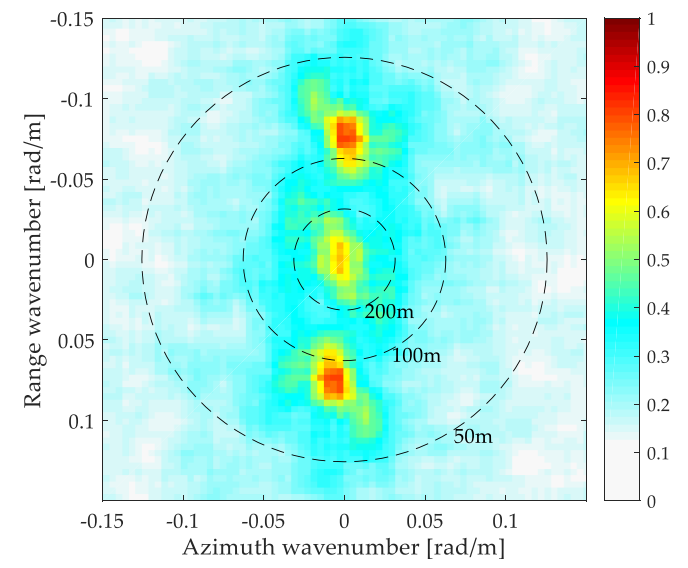

(b)

Figure 6. SAR image with two wave systems acquired by traditional imaging method and corresponding spectrum. (a) SAR image with two wave systems, but only a wave system can be observed. (b) Spectrum corresponding to SAR image.

The azimuthal autocorrelation function obtained from the SAR image spectrum is shown in Figure 7. Gaussian fitting is performed according to the Equation (1), and the azimuth cutoff $\lambda_{c}=44.80 \mathrm{~m}$ is calculated, which will be used to estimate significant wave height below.

The SAR SLC data is refocusing shown in Figure 6a. By traversing the focus setting variation section $\Delta V_{i} \in[V-50, V+50]$, the curve of the normalized peak-to-background ratio obtained changing with focus setting is shown in Figure 8.

As shown in Figure 8, the normalized peak-to-background ratio has two local maximum value, indicating that there are two wave systems on the the real ocean surface, namely $N u m=2$ and $\Delta \mathbf{V}_{\text {opt }}=\left[\Delta V_{o p t}^{1}, \Delta V_{o p t}^{2}\right]$. When $\Delta V_{o p t}^{1}=20 \mathrm{~m} / \mathrm{s}$, the refocusing quality of the first ocean waves is best. When $\Delta V_{o p t}^{2}=-30 \mathrm{~m} / \mathrm{s}$, the refocusing quality of the second ocean waves is best. 


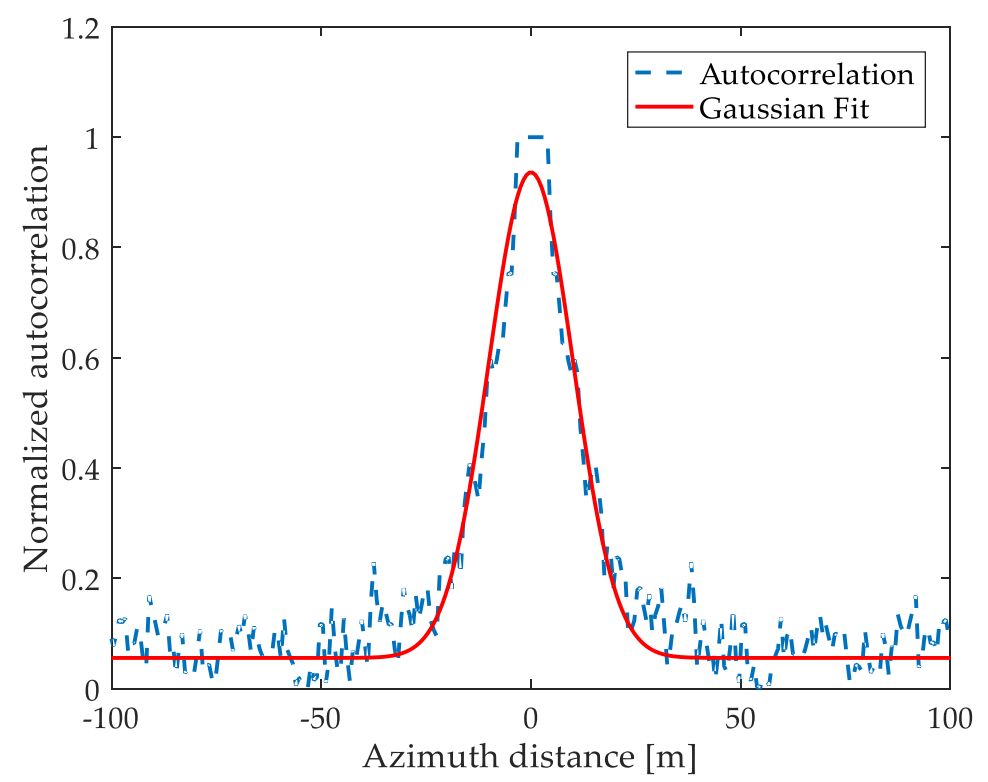

Figure 7. Azimuthal autocorrelation function and its Gaussian fitting results.

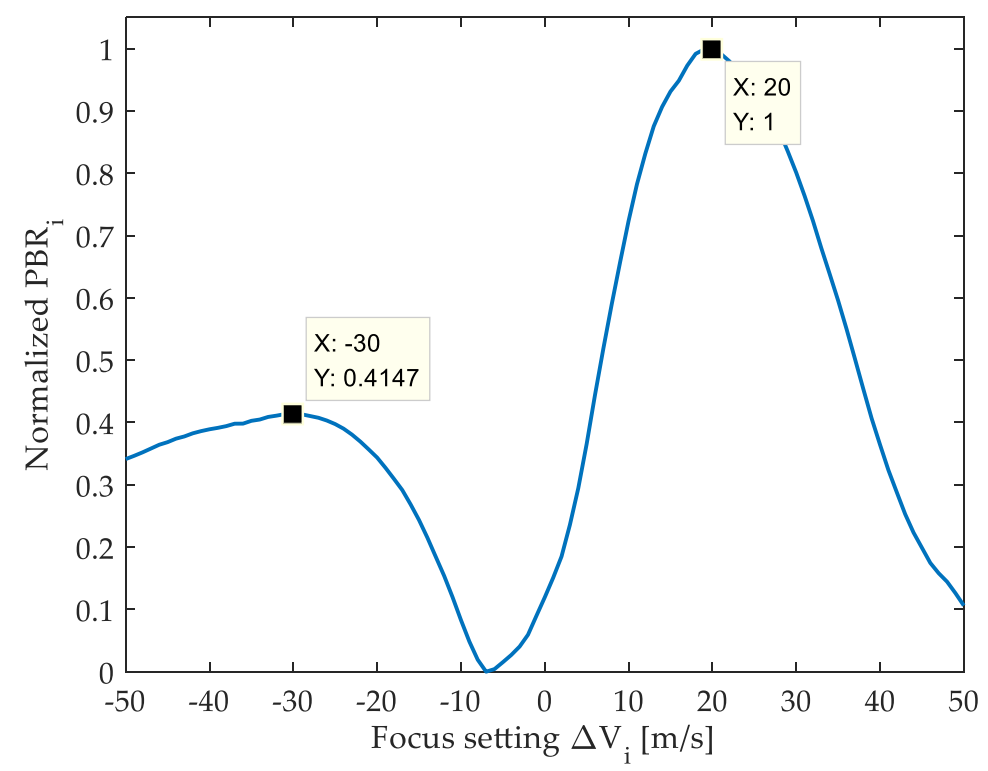

Figure 8. Normalized peak-to-background ratio curve with focus setting.

\subsubsection{Experiment of Significant Wave Height Estimation of the First Ocean Waves}

When $\Delta V_{o p t}^{1}=20 \mathrm{~m} / \mathrm{s}$, the refocused SAR image of the first ocean waves is shown in Figure 9a. The corresponding wave spectrum is shown in Figure 9b.

As shown in Figure 9a, it can be found that the contrast of ocean waves is greatly improved. Meanwhile, the wave spectrum is clearer in Figure 9b, which is more conducive to estimate significant wave height. Using the process shown in Figure 1, the wavelength $\lambda_{p}^{1}=78.87 \mathrm{~m}$ of ocean waves can be obtained. Due to $\Delta V_{o p t}^{1}>0$, the wave propagation direction after $180^{\circ}$ ambiguity removal is $\phi^{1}=191.24^{\circ}$. Finally, the significant wave height $S W H^{1}=0.45 \mathrm{~m}$ is calculated by Equation (19). 


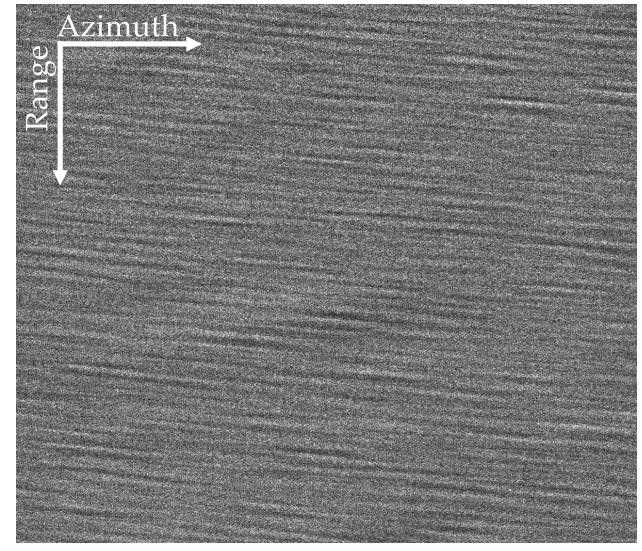

(a)

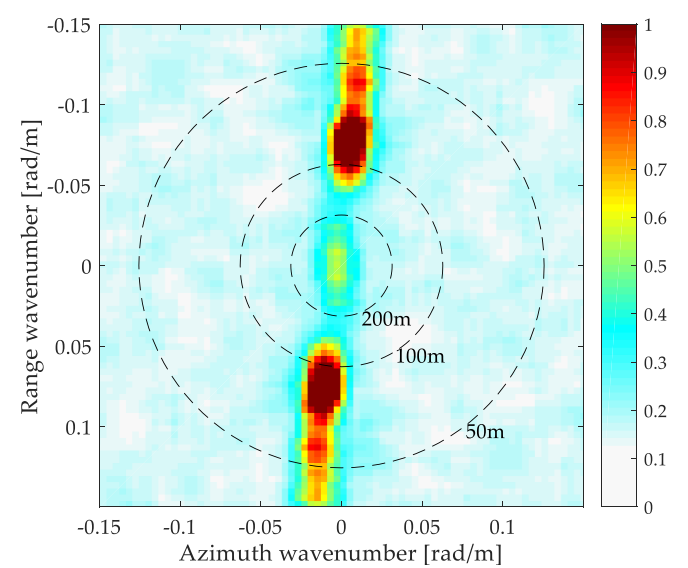

(b)

Figure 9. Refocused SAR image of the first ocean waves and corresponding spectrum. (a) Refocused SAR image with two wave systems. (b) Spectrum corresponding to refocused SAR image.

\subsubsection{Experiment of Significant Wave Height Estimation of the Second Ocean Wave}

When $\Delta V_{o p t}^{2}=-30 \mathrm{~m} / \mathrm{s}$, the refocused SAR image of the second ocean waves is shown in Figure 10a. The corresponding wave spectrum is shown in Figure 10b.

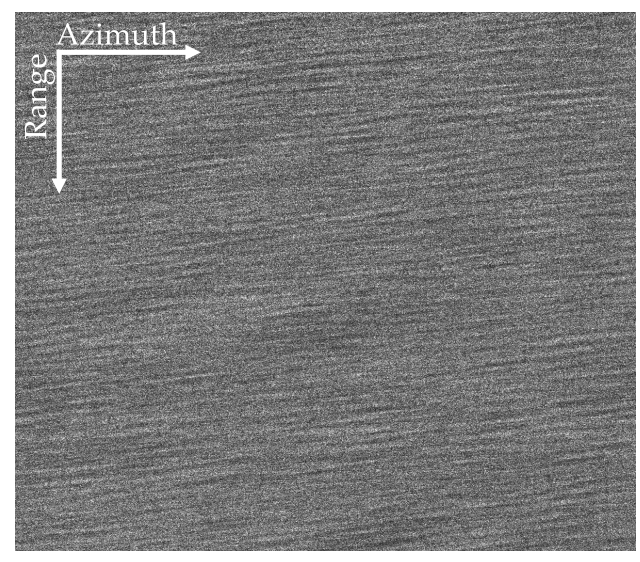

(a)

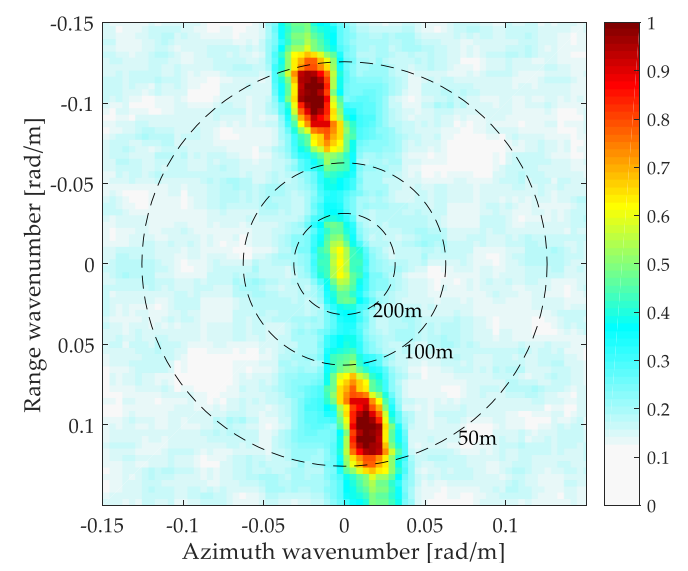

(b)

Figure 10. Refocused SAR image of the second ocean waves and corresponding spectrum. (a) Refocused SAR image with two wave systems. (b) Spectrum corresponding to refocused SAR image.

The completely invisible wave system in Figure 6a is shown in Figure 10a. As shown in Figure 10b, the wave spectrum is very clear, which is more conducive to estimate significant wave height. Using the process shown in Figure 1, the wavelength $\lambda_{p}^{2}=61.46 \mathrm{~m}$ of ocean waves can be obtained. Due to $\Delta V_{o p t}^{2}<0$, the wave propagation direction after $180^{\circ}$ ambiguity removal is $\phi^{2}=173.49^{\circ}$. Finally, the significant wave height $S W H^{2}=0.40 \mathrm{~m}$ is calculated by Equation (19).

\section{Validation of the Experimental Results With ECMWF and Sensitivity Analysis}

\subsection{Validation of the Experimental Results With ECMWF}

In order to verify the effectiveness of the proposed method, the experimental results of the proposed method are compared with the European Centre for medium-Range Weather Forecast (ECMWF) data. The spatial resolution of the ECMWF data is $0.5^{\circ} \times 0.5^{\circ}$. The time resolution is $1 h$. The comparison of SAR image significant wave height estimation results and ECMWF data are shown in Table 3. 
Table 3. Comparison of SAR image significant wave height estimation results and ECMWF data.

\begin{tabular}{|c|c|c|}
\hline & $\begin{array}{c}\text { Case } \\
\text { 1-Invisible Waves }\end{array}$ & Case 2-Two Wave Systems \\
\hline SAR acquisition time (UTC) & 2014.10.11 01:22 & 2014.9.14 01:29 \\
\hline SAR image central location & $\left(109.46^{\circ} \mathrm{E}, 17.27^{\circ} \mathrm{N}\right)$ & $\left(109.58^{\circ} \mathrm{E}, 17.27^{\circ} \mathrm{N}\right)$ \\
\hline Corresponding time of ECMWF (UTC) & 2014.10.11 01:00 & 2014.9.14 01:00 \\
\hline SWH from SAR image $(\mathrm{m})$ & 1.51 & 0.40 \\
\hline Corresponding SWH from ECMWF (m) & 1.52 & 0.30 \\
\hline
\end{tabular}

As is shown in Table 3, it could be found that significant wave heights are estimated for the cases of invisible waves and two wave systems. The time separation between the SAR acquisition time and the ECMWF time is within half an hour. The significant wave heights are very close to that of ECMWF, which fully demonstrates the effectiveness of the proposed method.

The space-time analysis is of great significance to verifying the accuracy of the proposed method [29-31]. In order to further illustrate the effectiveness of the proposed method, 10 sets of airborne SAR data with long integration times collected at different times are processed, and the estimation results of significant wave height are compared with the ECMWF data. The scatter plots of the significant wave height derived by the proposed method and the ECMWF data are shown in Figure 11. Quantitative analysis is performed by bias (BIAS), the root mean square error (RMSE), scatter index (SI) and correlation coefficient (COR). The equations are as follows:

$$
\begin{gathered}
\text { BIAS }=\frac{1}{N} \sum_{j=1}^{N}\left(x_{j}-y_{j}\right) \\
\text { RMSE }=\sqrt{\frac{1}{N} \sum_{j=1}^{N}\left(x_{j}-y_{j}\right)^{2}} \\
S I=\frac{1}{\left\langle x_{j}\right\rangle} \sqrt{\frac{1}{N} \sum_{j=1}^{N}\left[\left(y_{j}-\left\langle y_{j}\right\rangle\right)-\left(x_{j}-\left\langle x_{j}\right\rangle\right)\right]^{2}} \times 100 \% \\
\operatorname{COR}=\frac{\sum_{j=1}^{N}\left[\left(x_{j}-\left\langle x_{j}\right\rangle\right)\left(y_{j}-\left\langle y_{j}\right\rangle\right)\right]}{\sqrt{\sum_{j=1}^{N}\left(x_{j}-\left\langle x_{j}\right\rangle\right)^{2} \sum_{j=1}^{N}\left(y_{j}-\left\langle y_{j}\right\rangle\right)^{2}}}
\end{gathered}
$$

among them, $x_{j}$ and $y_{j}$ represent the significant wave height in ECMWF data and that obtained by the proposed method, respectively. $N$ is the number of verification data, and $\langle\cdot\rangle$ represents the average operator.

As shown in Figure 11, compared with the ECMWF data, the results of the significant wave height obtained by the proposed method have a bias of $0.06 \mathrm{~m}$, a root mean square error of $0.2 \mathrm{~m}$, a scatter index of $14.4 \%$, and a correlation coefficient of 0.95 . It can be found that the results of the proposed method are in good agreement with the ECMWF data. In addition, according to Figure 11, it can be seen that the estimation error of the significant wave height is basically stable within $0.2 \mathrm{~m}$, and the maximum error is about $0.5 \mathrm{~m}$. 


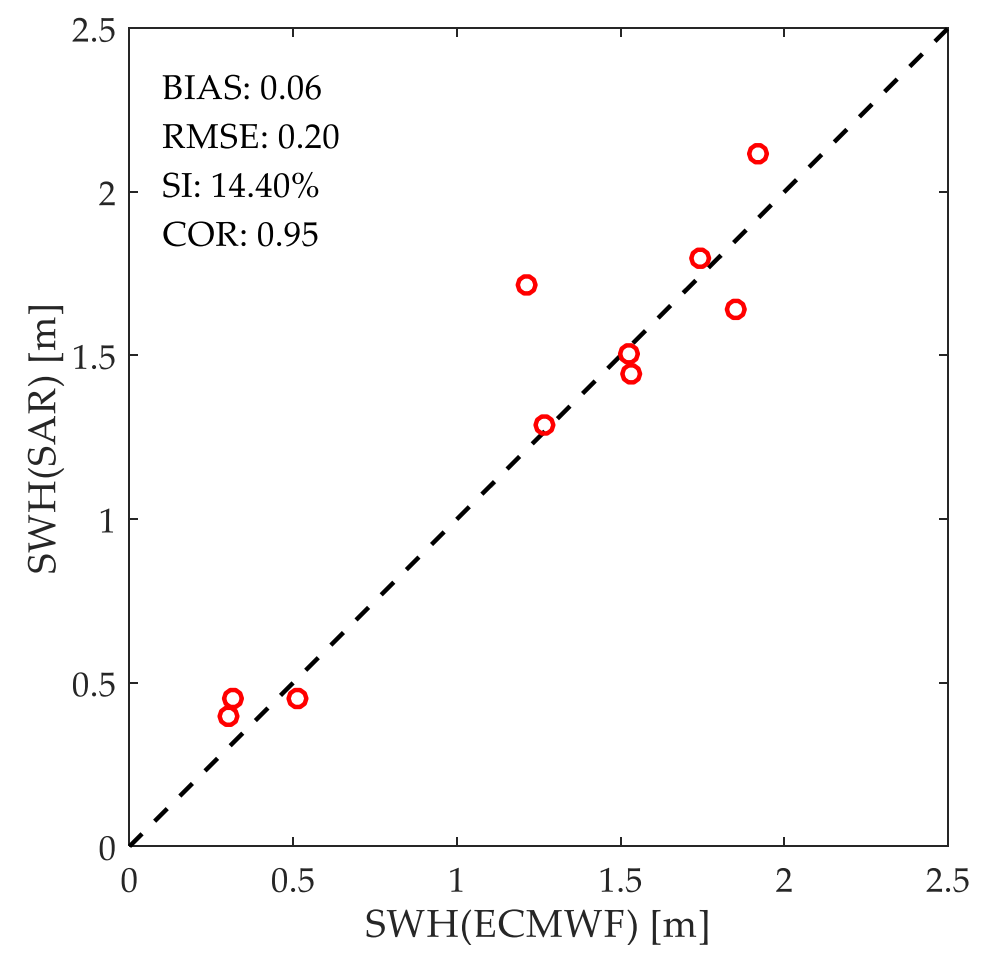

Figure 11. Scatter plots of the significant wave height derived by the proposed method and the ECMWF data.

\subsection{Sensitivity Analysis of Significant Wave Height Estimation}

As shown in Equation (19), the error of significant wave height estimation comes from the azimuth cutoff $\lambda_{c}$, wavelength $\lambda_{p}$ of ocean waves and propagation direction $\phi$ of ocean waves. Then, the sensitivity analysis of significant wave height estimation will be carried out with the parameters referring to Section 3.1. The parameters are shown in Table 4. The sensitivity of the estimating significant wave height $S W H$ to the parameter $Z$ is defined as

$$
S_{Z}=\frac{\partial(S W H)}{\partial Z}
$$

where $Z \in\left[\lambda_{c}, \lambda_{p}, \phi\right]$.

Table 4. The parameters using in sensitivity analysis.

\begin{tabular}{ccc}
\hline Parametric Name & Parametric Symbol & Parametric Value \\
\hline Azimuth cutoff $(\mathrm{m})$ & $\lambda_{c}$ & 90 \\
Wavelength of ocean waves $(\mathrm{m})$ & $\lambda_{p}$ & 240 \\
Propagation direction of ocean waves $\left(^{\circ}\right)$ & $\phi$ & 300 \\
\hline
\end{tabular}

\subsubsection{Sensitivity Analysis of Significant Wave Height to Azimuth Cutoff}

According to Equation (19), the significant wave height is proportional to the azimuth cutoff $\lambda_{c}$. When the azimuth cutoff error increases, the estimation error of significant wave height will also increase. In order to analyze the sensitivity of the significant wave height to the azimuth cutoff $\lambda_{c}$, it is necessary to assume that the wavelength $\lambda_{p}$ of ocean waves and propagation direction $\phi$ of ocean waves remain unchangeable. Due to $\lambda_{p}=240 \mathrm{~m}$, the sensitivity is analyzed within $\lambda_{c} \in[10 \mathrm{~m}, 200 \mathrm{~m}]$, and the sensitivity curve of significant wave height to azimuth cutoff is shown in Figure 12. 


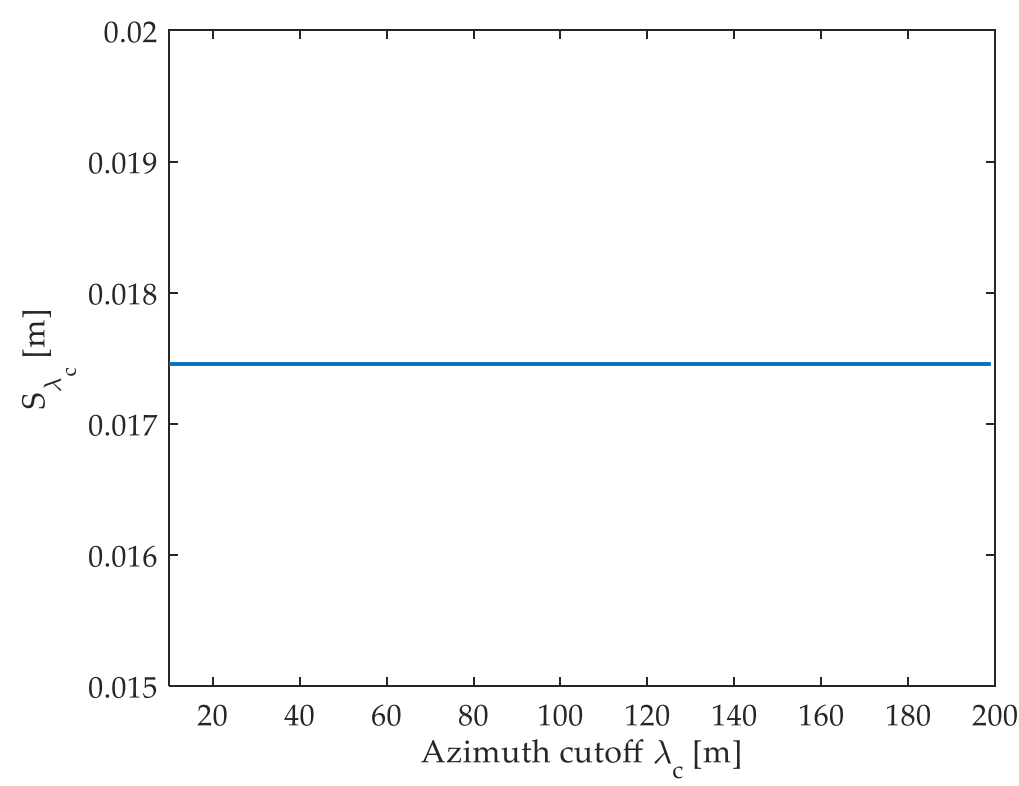

Figure 12. Sensitivity curve of significant wave height to azimuth cutoff.

As shown in 12, no matter how the azimuth cutoff changes, the sensitivity does not change. In other words, the sensitivity of the significant wave height to the azimuth cutoff is independent of the azimuth cutoff itself.

\subsubsection{Sensitivity Analysis of Significant Wave Height to Wavelength of Ocean Waves}

According to Equation (19), the significant wave height is proportional to the square of wavelength $\lambda_{p}$ of ocean waves. When the wavelength $\lambda_{p}$ of ocean waves error increases, the estimation error of significant wave height will also increase. In order to analyze the sensitivity of the significant wave height to the wavelength $\lambda_{p}$ of ocean waves, it is necessary to assume that the azimuth cutoff $\lambda_{c}$ and propagation direction $\phi$ of ocean waves keep unchangeable. Due to $\lambda_{c}=90 \mathrm{~m}$, the sensitivity is analyzed within $\lambda_{p} \in[100 \mathrm{~m}, 400 \mathrm{~m}]$, and the sensitivity curve of significant wave height to wavelength of ocean waves is shown in Figure 13.

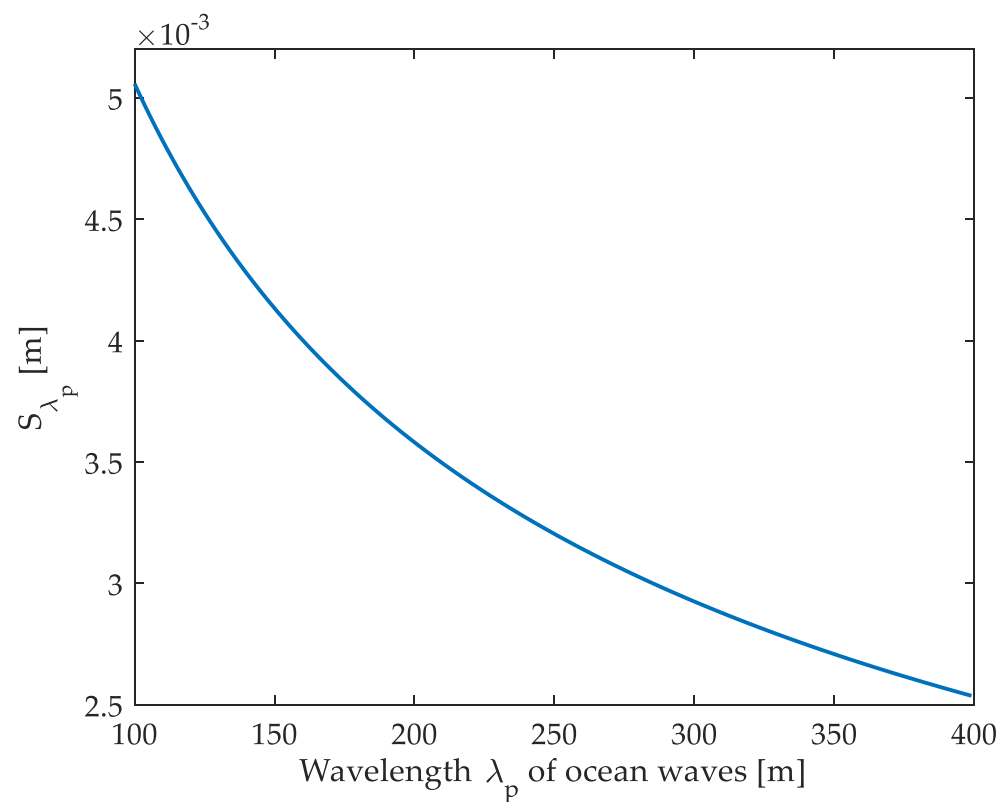

Figure 13. Sensitivity curve of significant wave height to wavelength of ocean waves. 
It can be seen from Figure 13 that with the increase of the wavelength of ocean waves, the sensitivity of significant wave height estimation gradually decreases, which indicates that with the increase of the wavelength of ocean waves, the influence of the wavelength of ocean waves error on the significant wave height decreases.

\subsubsection{Sensitivity Analysis of Significant Wave Height to Propagation Direction of Ocean Waves}

According to Equation (19), it is nonlinear between the significant wave height and the propagation direction $\phi$ of ocean waves, and the estimation error of the significant wave height is affected by the real propagation direction $\phi$ of ocean waves and the error values. For a given propagation direction $\phi$ of ocean waves, the estimation error of significant wave height changes nonlinearly with the increase of propagation direction error of ocean waves. In order to analyze the sensitivity of the significant wave height to the propagation direction $\phi$ of ocean waves, it is assumed that the azimuth cutoff $\lambda_{c}$ and the wavelength $\lambda_{p}$ of ocean waves remain unchangeable. The sensitivity curve of the significant wave height to the propagation direction $\phi$ of ocean waves within the range of $\phi \in\left[0^{\circ}, 360^{\circ}\right]$ is shown in Figure 14 .

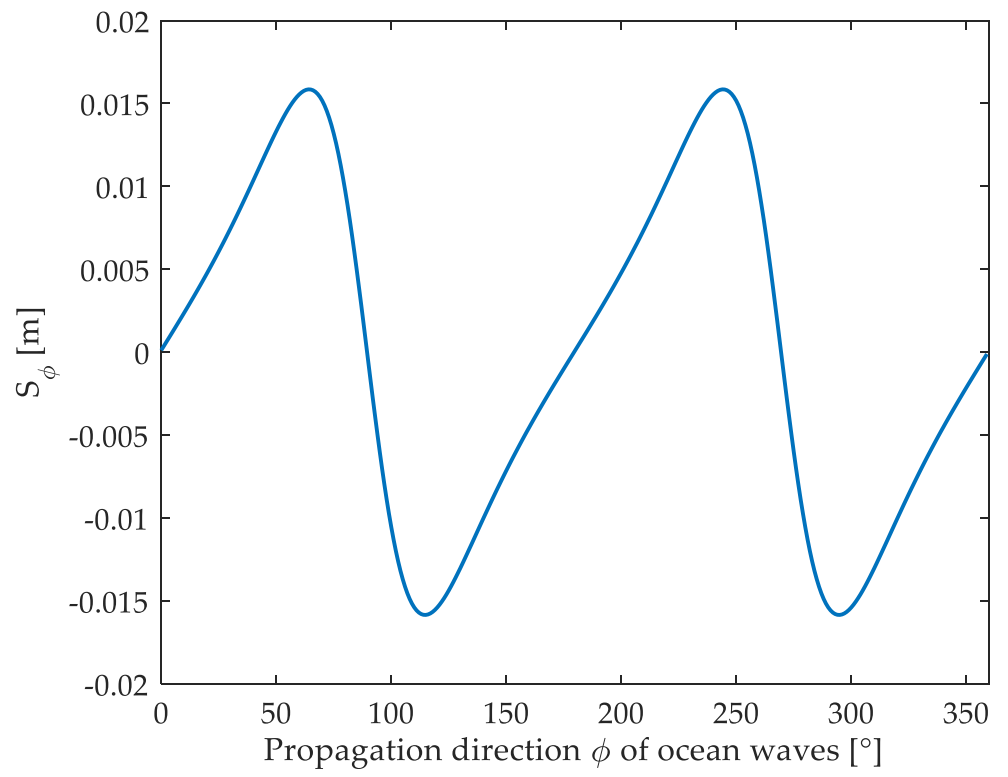

Figure 14. Sensitivity curve of significant wave height to propagation direction of ocean waves.

As shown in Figure 14, the sensitivity of the significant wave height to the propagation direction of ocean waves is nonlinear. When the propagation direction of ocean waves is $\phi=64^{\circ}, 115^{\circ}, 244^{\circ}, 295^{\circ}$, the propagation direction error of ocean waves has the greatest impact on the result of significant wave height estimation. When the propagation direction of ocean waves is $\phi=0^{\circ}, 90^{\circ}, 180^{\circ}, 270^{\circ}, 360^{\circ}$, the propagation direction error of ocean waves has the least impact on the result of significant wave height estimation.

\section{Conclusions}

When long integration time SAR observes the ocean, the motion of ocean waves will have a great impact on the imaging quality, resulting in waves blurred or even invisible in SAR images. For low-frequency SAR (such as P-band, L-band) data with long integration times, the following two problems are more prominent. (1) The ocean waves are usually invisible in SAR images. It is impossible to estimate significant wave height by means of the present methods. (2) In the case that there are multiple wave systems on the real ocean surface, significant wave height of only one wave system can be estimated for the reason that only a blurred wave system can be observed in SAR images.

In order to solve the above two problems, a method of estimating significant wave height from SAR with long integration times is proposed in this paper. Firstly, the azimuth 
cutoff is calculated from SLC data. Then, each ocean wave system is refocused based on the optimum focus setting, respectively. Next, the wavelength and propagation direction of each wave system are calculated from the refocused images. At the same time, the $180^{\circ}$ ambiguity of wave propagation direction is removed without any additional processing. Finally, significant wave height is estimated. The proposed method has been verified by two airborne SAR data with long integration times. One is a case of invisible ocean waves. The other is a case of two ocean wave systems. Compared with the ECMWF data, the results show that the significant wave heights are very close to that of ECMWF, and the error is basically stable at $0.2 \mathrm{~m}$, which sufficiently demonstrate the effectiveness of the proposed method.

Further, the sensitivity of the significant wave height to the azimuth cutoff, the wavelength of ocean waves and propagation direction of ocean waves is analyzed. The results show that the sensitivity of the significant wave height to the azimuth cutoff is independent of the azimuth cutoff itself. With the increase of the wavelength of ocean waves, the influence of the wavelength error of ocean waves on the significant wave height is reduced. The sensitivity of the significant wave height to the propagation direction of ocean waves is nonlinear. Moreover, comparing Figures 12-14, it could be found that the wavelength error of ocean waves has the least influence on the estimation result of the significant wave height, the error of azimuth cutoff has the most obvious influence on the estimation result of the significant wave height, and the influence of the propagation direction error on the estimation result of the significant wave height depends on the actual propagation direction.

When the wave texture is invisible in SAR images with the long integration times, the present methods cannot estimate the significant wave height. The proposed method can overcome the limitation of the present methods. Compared with the present methods, some steps such as ocean refocusing in Section 2.3 are added. Therefore, the proposed method increases the cost of computation compared with the present methods. However, the proposed method does not increase the time complexity compared with the present methods. For the SLC data of $P_{a z i} \times P_{r g}$ (point number in azimuth $\times$ point number in range), the time complexity is $O\left[P_{a z i} \times P_{r g} \times \lg \left(P_{a z i} \times P_{r g}\right)\right]$.

The proposed method is suitable for the significant wave height estimation of ocean waves when the waves are invisible in SAR images with long integration times. When the proposed method is applied to estimating significant wave height from SAR with long integration times, it needs to be satisfied that a sub-block data can be chosen in accordance with Section 2.1. In addition, the proposed method can be well applied to other SAR with long integration times, such as spotlight SAR, circular SAR and geosynchronous SAR under development.

Author Contributions: All authors have made some contributions to the article from different aspects. Conceptualization, J.C.; investigation, Y.Z.; software, Y.Z. and Z.L.; writing—original draft preparation, Y.Z., X.W., L.D.; writing—review and editing, Y.Z., Z.L. and X.W. All authors have read and agreed to the published version of the manuscript.

Funding: This research received no external funding.

Institutional Review Board Statement: Not applicable.

Informed Consent Statement: Not applicable.

Data Availability Statement: Data sharing not applicable.

Acknowledgments: The authors would like to thank the anonymous reviewers for their constructive comments and recommendations.

Conflicts of Interest: The authors declare no conflict of interest. 


\section{References}

1. Vachon, P.W.; Monaldo, F.M.; Holt, B.; Lehner, S. Ocean surface waves and spectra. In Synthetic Aperture Radar: Marine User's Manual; Jackson, C.R., Apel, J.R., Eds.; U.S. Department of Commerce National Oceanic and Atmospheric Administration: Washington, DC, USA, 2004; pp. 139-169.

2. Hasselmann, K.; Hasselmann, S. On the nonlinear mapping of an ocean wave spectrum into a synthetic aperture radar image spectrum and its inversion. J. Geophys. Res. Ocean. 1991, 96, 10713-10729. [CrossRef]

3. Hasselmann, S.; Brüning, C.; Hasselmann, K.; Heimbach, P. An improved algorithm for the retrieval of ocean wave spectra from synthetic aperture radar image spectra. J. Geophys. Res. Ocean. 1996, 101, 16615-16629. [CrossRef]

4. Hasselmann, S.; Hasselmann, K.; Baure, E.; Janssen, P.A.E.M.; Komen, G.J.; Bertotti, L.; Lionello, P.; Guillaume, A.; Cardone, V.C.; Greenwood, J.A.; et al. The WAM model-A third generation ocean wave prediction model. J. Phys. Oceanogr. 1988, $18,1775-1810$.

5. Mastenbroek, C.; De Valk, C.F. A semiparametric algorithm to retrieve ocean wave spectra from synthetic aperture radar. J. Geophys. Res. Ocean. 2000, 105, 3497-3516. [CrossRef]

6. Sun, J.; Guan, C. Parameterized first-guess spectrum method for retrieving directional spectrum of swell-dominated waves and huge waves from SAR images. Chin. J. Oceanol. Limnol. 2006, 24, 12-20.

7. Ren, L.; Yang, J.; Mouche, A.; Wang, H.; Wang, J.; Zheng, G.; Zhang, H. Preliminary analysis of Chinese GF-3 SAR quadpolarization measurements to extract winds in each polarization. Remote Sens. 2017, 9, 1215. [CrossRef]

8. Schulz-Stellenfleth, J.; König, T.; Lehner, S. An empirical approach for the retrieval of integral ocean wave parameters from synthetic aperture radar data. J. Geophys. Res. Ocean. 2007, 112, C03019. [CrossRef]

9. Li, X.; Lehner, S.; Bruns, T. Ocean wave integral parameter measurements using Envisat ASAR wave mode data. IEEE Trans. Geosci. Remote Sens. 2011, 49, 155-174. [CrossRef]

10. Stopa, J.E.; Mouche, A. Significant wave heights from Sentinel-1 SAR: Validation and applications. J. Geophys. Res. Ocean. 2017, 122, 1827-1848. [CrossRef]

11. Wang, H.; Wang, J.; Yang, J.; Ren, L.; Zhu, J.; Yuan, X.; Xie, C. Empirical algorithm for significant wave height retrieval from wave mode data provided by the Chinese Satellite Gaofen-3. Remote Sens. 2018, 10, 363. [CrossRef]

12. Ren, L.; Yang, J.; Zheng, G.; Wang, J. Significant wave height estimation using azimuth cutoff of C-band Radarsat-2 singlepolarization SAR images. Acta Oceanol. Sin. 2015, 34, 93-101. [CrossRef]

13. Shao, W.; Zhang, Z.; Li, X.; Li, H. Ocean wave parameters retrieval from Sentinel-1 SAR imagery. Remote Sens. 2016, 8, 707. [CrossRef]

14. Pramudya, F.S.; Pan, J.; Devlin, A.T.; Lin, H. Enhanced estimation of significant wave height with dual-polarization Sentinel-1 SAR imagery. Remote Sens. 2021, 13, 124. [CrossRef]

15. Alpers, W.; Rufenach, C. The effect of orbital motions on synthetic aperture radar imagery of ocean waves. IEEE Trans. Antennas Propag. 1979, 27, 685-690. [CrossRef]

16. Raney, R. Wave orbital velocity, fade, and SAR response to azimuth waves. IEEE J. Ocean. Eng. 1981, 6, 140-146. [CrossRef]

17. Beal, R.C.; Tilley, D.G.; Monaldo, F.M. Large- and small-scale spatial evolution of digitally processed ocean wave spectra from Seasat synthetic aperture radar. J. Geophys. Res. Atmos. 1983, 88, 1761-1778. [CrossRef]

18. Vachon, P.W.; Krogstad, H.E.; Paterson, J.S. Airborne and spaceborne synthetic aperture radar observations of ocean waves. Atmosphere-Ocean 1994, 32, 83-112. [CrossRef]

19. Tajirian, E.K. Multifocus processing of L band synthetic aperture radar images of ocean waves obtained during the tower ocean wave and radar dependence experiment. J. Geophys. Res. Ocean. 1988, 93, 13849-13857. [CrossRef]

20. Hayt, D.W.; Alpers, W.; Burning, C.; Dewitt, R.; Henyey, F.; Kasilingam, D.P.; Keller, W.C.; Lyzenga, D.R.; Plant, W.J.; Schult, R.L.; et al. Focusing simulations of synthetic aperture radar ocean images. J. Geophys. Res. Ocean. 1990, 95, 16245-16261. [CrossRef]

21. Kasilingam, D.P.; Hayt, D.W.; Shemdin, O.H. Focusing of synthetic aperture radar ocean images with long integration times. J. Geophys. Res. 1991, 96, 16935-16942. [CrossRef]

22. Wei, X.; Chong, J.; Zhao, Y.; Li, Y.; Yao, X. Airborne SAR imaging algorithm for ocean waves based on optimum focus setting. Remote Sens. 2019, 11, 564. [CrossRef]

23. Jain, A.; Shemdin, O.H. L band SAR ocean wave observations during MARSEN. J. Geophys. Res. Ocean. 1983, 88, 9792-9808. [CrossRef]

24. Lyzenga, D.R. Numerical simulation of synthetic aperture radar image spectra for ocean waves. IEEE Trans. Geosci. Remote Sens. 1986, GE-24, 863-872. [CrossRef]

25. Hwang, P.A.; Toporkov, J.V.; Sletten, M.A.; Menk, S.P. Mapping surface currents and waves with interferometric synthetic aperture radar in coastal waters: Observations of wave breaking in swell-dominant conditions. J. Phys. Oceanogr. 2013, 43, 563-582. [CrossRef]

26. Engen, G.; Johnsen, H. SAR-ocean wave inversion using image cross spectra. IEEE Trans. Geosci. Remote Sens. 1995, 33, 1047-1056. [CrossRef]

27. Bao, M.; Alpers, W. On the cross spectrum between individual-look synthetic aperture radar images of ocean waves. IEEE Trans. Geosci. Remote Sens. 1998, 36, 922-932. 
28. Ouchi, K.; Burridge, D.A. Resolution of a controversy surrounding the focusing mechanisms of synthetic aperture radar images of ocean waves. IEEE Trans. Geosci. Remote Sens. 1994, 32, 1004-1016. [CrossRef]

29. Laface, V.; Arena, F.; Guedes Soares C. Directional analysis of sea storms. Ocean. Eng. 2015, 107, 45-53. [CrossRef]

30. Romolo A.; Arena F. On Adler space-time extremes during ocean storms. J. Geophys. Res. Ocean. 2015, 120, 3022-3042. [CrossRef]

31. Romolo A.; Malara G.; Laface V.; Arena F. "Space-time long-term statistics of ocean storms", Probabilistic Engineering Mechanics. Probab. Eng. Mech. 2015, 44, 150-162. [CrossRef] 